\title{
REVISTA
}

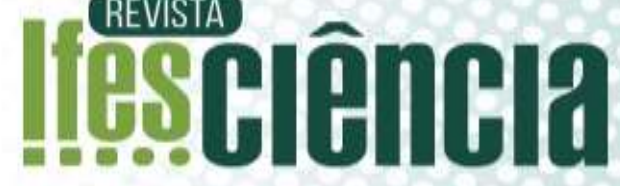

\section{RESGATE DA MEMÓRIA DOS PERSEGUIDOS POLÍTICOS NO BRASIL: CURRICULOS E SABERES EMANCIPATÓRIOS}

\author{
RESCUE OF THE MEMORY OF THE VICTIMS OF POLITICAL \\ PERSECUTION IN BRAZIL: RESUMES AND EMANCIPATORY \\ KNOWLEDGE
}

\author{
Yuri Miguel Macedo ${ }^{1}$ \\ Gilsilene Passon Picoretti Francischetto ${ }^{2}$
}

\begin{abstract}
${ }^{1}$ Programa de Pós-Graduação em Ensino e Relações Étnico-Raciais da Universidade Federal do Sul da Bahia UFSB. E-mail: yurimacedo@csc.ufsb.br. ${ }^{2}$ Programa de Pós-Graduação Stricto Sensu em Direitos e Garantias Fundamentais da Faculdade de Direito de Vitória. E-mail: gilsilenepasson@uol.com.
\end{abstract}

Artigo submetido em 05/03/2019, aceito em 15/06/2019 e publicado em 15/09/2019.

Resumo: Esta pesquisa apresenta reflexões acerca da importância do resgate da memória em torno da resistência ao regime militar no Brasil como um elemento fundamental na construção de uma educação emancipatória. Para que possa efetivar a justiça transicional em nosso país o caminho passaria por um novo projeto educativo, não necessariamente escolar, em que as memórias reveladas possam ter espaços de visibilidade e compor os horizontes de sentido histórico das novas gerações. Assim, a pergunta que norteia o presente artigo é: De que forma um projeto educativo emancipatório utilizaria a memória como fator de potencialização da tomada de consciência dos indivíduos?

Palavras-chave: Currículo; perseguidos políticos; memória; educação; direitos.

\begin{abstract}
This article seeks to reflect on the importance of rescuing the memory of resistance to the military regime in Brazil as a fundamental element in the construction of an emancipatory educational project. In order for us to implement transitional justice in our country, the path would be a new educational project, not necessarily a school project, in which the revealed memories can have spaces of visibility and compose the horizons of the historical sense of the new generations. Thus, the question that guides this article is: In what way an emancipatory educational project would use memory as a factor of empowerment of the individuals' awareness?
\end{abstract}

Keywords: Curriculum; persecuted politicians; memory; education; rights.

\section{ACESSO DAS NOVAS GERAÇÕES AO CONTEÚDO DA MEMÓRIA}

A Ditadura militar, instaurada pelo golpe de 1964, foi fortemente marcada pela violação de uma série de direitos, na qual a própria ordem jurídica foi utilizada para dar o amparo ao sistema que se erguia no
Brasil. Foram milhares de pessoas, entre mortos e desaparecidos, submetidos a inúmeras formas de tortura e exílios ${ }^{1}$.

\footnotetext{
1 Foram 353 vítimas fatais do regime militar e milhares de presos e torturados, perseguidos,
} 
Diante de todas as atrocidades cometidas pelo Regime militar, muitos resistiram e se organizaram pela retomada da democracia. Uma dessas lutas foi pela anistia, que contou com a participação de organizações da sociedade civil (Comitês Brasileiros pela Anistia - CBAS em 1978). É preciso salientar que a Lei $2.225 / 1985$ que foi aprovada não foi a reivindicada socialmente, na medida em que se estendeu seus efeitos aos agentes do estado que torturaram e mataram. Com a Lei 6.683/79, já constatamos um momento importante de sufocamento da memória dos fatos ocorridos. Assim:

O instituto da Anistia, nesses casos e a partir desse enfoque, reproduz aquele vício de origem que está na própria concepção da democracia moderna: o de substituir injustiça por igualdade, reforçando o apelo para uma sociedade amnésica. A concepção de anistia que a vê como um exercício de esquecimento, infelizmente, ainda é preponderante nas experiências de transição vivenciadas pelos estados ao longo dos anos (SILVA FILHO, 2010, p. 195-196).

A Arguição de Descumprimento de Preceito Fundamental (ADPF), $n^{\circ} 153$, que questionava o Art. $1^{\circ} \S 1^{\circ}$ da Lei de anistia, no sentido de que os crimes políticos e conexos não incluíssem os crimes cometidos por agentes, como a tortura, estupros, homicídios, ao ser objeto de decisão pelo Supremo Tribunal Federal, foi considerada por maioria de votos (7 a 2) em consonância com o "acordo" político da época e que, portanto, não merece outra interpretação. Vê-se aqui uma clara utilização da anistia como política de esquecimento. O relator, ministro Eros Grau, no governo de Lula, argumentou que não caberia ao judiciário rever tal "acordo" político.

O foco da presente análise volta-se para os perseguidos políticos do Regime

exonerados de seus cargos públicos, conforme dados da Comissão Especial de Mortos e Desaparecidos Políticos. militar, mas é possível verificar inúmeras outras situações vivenciadas por pessoas e grupos em nosso país que foram relegadas ao esquecimento. Temos o massacre de índios, desde o período inicial da colonização, a coisificação do negro, que foi trazido para o trabalho escravo, as perseguições diversas, são alguns exemplos de como a história do Brasil mostra-se atravessada por inúmeros fatos de afronta ao ser humano e que não são relembrados ou são considerados como o preço que se pagou para o progresso.

Tais silenciamentos, ou versões parciais $^{2}$ da história, constituíram-se em obstáculos enormes de resgate da memória, impedindo que as novas gerações pudessem incluir tais memórias em seus horizontes de sentido, já que foi excluída a possibilidade ampla de simbolização das atrocidades cometidas e de como, nos dias atuais, ainda carregamos a herança de tais atos violentos, que se repetem em diferentes momentos e instâncias sociais.

Neste contexto, surge a necessidade de colocarmos a memória como uma condição para uma ressignificação dos fatos ocorridos no passado. Não se trata de apagar a versão que nos foi passada da história, mas colocá-la como apenas um elemento na arena de narrativas disponíveis, para que as novas gerações possam acessar as várias memórias que marcaram o período de Regime militar e incluí-los em suas reflexões. Tal esforço estaria ligado ao que Boaventura de Sousa Santos (2006, p. 120) chamou de sociologia das ausências, que busca expandir o domínio das experiências sociais disponíveis, mas que, muitas vezes, estão invisibilizadas.

\footnotetext{
2 Não só versões parciais como também completamente distanciadas dos fatos ocorridos. Vejamos o exemplo do assassinato de Vladimir Herzog, cuja versão oficial era a de que teria havido um suicídio, quando na verdade houve assassinato. Em 2013, quase 40 anos depois do fato, a família recebeu a certidão de óbito retificada com a declaração do verdadeiro motivo da morte, qual seja, a tortura a que ele foi submetido.
} 
O autor associa a tal procedimento sociológico um outro, que denominou de sociologia das emergências e complementa:

As duas sociologias estão estreitamente associadas, visto que quanto mais experiências estiverem hoje disponíveis no mundo mais experiências são possíveis no futuro. Quanto mais ampla for a realidade credível, mais vasto é o campo dos sinais ou pistas credíveis e dos futuros possíveis e concretos. Quanto maior for a multiplicidade $\mathrm{e}$ diversidade das experiências disponíveis e possíveis (conhecimentos e agentes), maior será a expansão do presente e a contração do futuro. (SANTOS, 2006, p. 120)

Com a desinvisibilização de tais memórias ocorridas no período de exceção, abre-se a possibilidade real para que aqueles que experienciaram a memória possam falar e trazer as suas percepções sobre o ocorrido, num exercício de sociologia das ausências. Com isso as novas gerações também poderão acessar tais memórias, mesmo não as tendo vivenciado diretamente, poderão pautar sua compreensão da realidade em outros elementos e desenvolver uma relação de pertencimento com tais histórias, compreendendo que o presente foi constituído com base também em muito sofrimento humano. Conforme nos coloca Boaventura de Sousa Santos:

\begin{abstract}
A mesma teoria da história contribuiu para trivializar, banalizar os conflitos e o sofrimento humano de que é feita a repetição do presente (...). O sofrimento humano mediatizado pela sociedade da informação está transformado numa telenovela interminável em que as cenas dos próximos capítulos são sempre diferentes e sempre iguais às cenas dos capítulos anteriores (1996, p. 16).
\end{abstract}

A memória auxiliaria não apenas no olhar para o passado, mas para a análise do presente auxiliando as pessoas que não vivenciaram as atrocidades do Regime militar e atribuir significados aos fatos e entender muitos dos avanços (inclusive no campo normativo) que a luta dessas pessoas fomentou. Com isso, é possível pensarmos na construção de uma consciência coletiva sobre a nossa história.

A memória enquanto categoria teórica vem sendo pensada em várias áreas do conhecimento, mas no presente texto a atenção está voltada para a memória como produto da experiência cultural. Uma referência fundamental neste sentido está na construção de Maurice Halbwachs (1990) para quem toda memória individual se construiria dentro de quadros socialmente definidos pelo grupo em que estamos inseridos. Para ele, a possibilidade de recordar só é possível quando os indivíduos se colocam diante do ponto de vista dos grupos sociais a que pertencem.

Fabiana Santos Dantas, referindo-se ao passado de vários países da América Latina, afirma que ele é marcado por violências e suas memórias estão alicerçadas em dois pilares que seriam a construção da versão oficial da história e o esquecimento proposital dos fatos desconformes. Complementa:

A política conciliatória do
esquecimento contempla seis
elementos bem caracterizados: a
produção da memória oficial sem os
fatos inadequados, a concessão de
anistias, a fabricação do consenso
(discurso da superação das
ideologias), o simples silenciar sobre
os fatos conflituosos, a busca da
reconciliação nacional e as
comemorações das datas cívicas
(2010, p. 56).

Vemos que na história do Brasil, especificamente quanto ao período de Ditadura militar, vários dos mecanismos acima citados foram amplamente utilizados. A consequência disso está na fragilidade que verificamos no resgate da memória relativa a tal período e na resistência que muitas pessoas ainda têm quanto à implementação de medidas de 
reparação aos perseguidos políticos em nosso país ${ }^{3}$.

O fortalecimento da memória constitui um passo fundamental no projeto de justiça transicional que o Brasil está desenvolvendo. Tamanha a sua importância que é possível tratá-la como direito fundamental. Neste sentido, Fabiana Santos Dantas coloca que:

(...) pode-se afirmar que o direito à memória existe e consiste no poder de acessar utilizar, reproduzir e transmitir o patrimônio cultural, com o intuito de aprender as experiências pretéritas da sociedade e assim acumular conhecimentos e aperfeiçoá-los através do tempo (...) Portanto, pode-se afirmar que o direito à memória pode ser concebido como fundamental simplesmente porque, sem ele, a sociedade brasileira perderia o seu fundamento de coesão (2010, p. 66-67).

Diante da fundamentalidade do direito à memória, é preciso pensar em medidas concretas para a sua efetivação. Assim, o próximo tópico trará uma análise dos mecanismos de resgate da memória que temos no Brasil.

\section{MECANISMOS DE JUSTIÇA TRANSICIONAL NO BRASIL}

Podemos considerar que a Justiça de Transição consiste num conjunto de medidas que buscam construir novas bases jurídicas, políticas, éticas e sociais em momentos pós-conflitos traumáticos de uma sociedade em que tenham ocorrido graves violações aos Direitos Humanos.

No Brasil, podemos verificar vários mecanismos que têm auxiliado nesse processo transicional. A Constituição Federal de 1988 trouxe uma previsão importante no art. $8 .^{\circ}$ do Ato das Disposições Constitucionais Transitórias

\footnotetext{
${ }^{3}$ Ainda é possível verificar informações veiculadas na mídia referindo-se às indenizações pagas aos perseguidos políticos como "bolsa ditadura", num sentido de associar a visão de que tais valores não seriam devidos ou seriam abusivos.
}

(ADCT) ao prever na lei regulamentadora $10.559 / 02$, em seu artigo $1^{\circ}$, inciso II, a possibilidade de indenização aos que sofreram danos em decorrência dos atos praticados pelo Estado, durante o Regime militar.

Outro passo importante foi a edição da Lei $n^{\circ}$ 9.140/95, que criou a Comissão Especial sobre Mortos e Desaparecidos Políticos que teve como uma de suas tarefas a localização de restos mortais e o reconhecimento oficial por parte do Estado dos assassinatos e desaparecimentos durante a ditadura. Acerca do trabalho da Comissão, expõe Marcelo D. Torelly (2010, p. 114-115):

Como resultado de seus trabalhos de reconhecimento, em 2007, a Comissão publicou o livro-relatório Direito à Memória e à verdade. Tratase do primeiro documento oficial do Estado Brasileiro a reconhecer a prática de torturas, assassinatos e desaparecimentos forçados enquanto prática sistemática durante os anos de ditadura (...).

O trabalho desenvolvido pela Comissão representou uma medida de grande relevância para $\mathrm{o}$ resgate da memória no nosso país. Quanto a este aspecto, Marcelo D. Torelly diz que:

\begin{abstract}
Ao resgatar essas histórias a comissão resgata o estado de Direito, relegado a um Estado de fato, uma vez que mesmo sem punir os agentes delinquentes que cometeram crimes em nome do estado, reconhece a existência destes crimes, impedindo que aos olhos da sociedade os mesmos se naturalizem enquanto práticas aceitáveis de controle social. (2010, p. 115)
\end{abstract}

Em 2001, foi editada a Medida Provisória $\mathrm{n}^{\mathrm{o}} 2.151$ que tratou dos direitos dos perseguidos políticos pela ditadura, como a declaração da condição de anistiado, o caráter indenizatório, a contagem de tempo do afastamento das atividades, conclusão de cursos superiores que foram interrompidos etc. 
No ano de 2002, regulamentando a Constituição Federal de 1988 e revogando a Medida Provisória 2.151/01, houve a edição da MP 65/02 convertida na Lei $n^{\circ}$ $10.559 / 02$, que veio regulamentar o direito à indenização, sendo atribuída tal tarefa à Comissão de Anistia, ligada ao Ministério da Justiça. É importante salientar que a Comissão não desempenha apenas a tarefa de apreciar e julgar os requerimentos de anistia que lhes são endereçados e suas respectivas indenizações, mas tem desenvolvido inúmeras outras atividades que contribuem para um avanço na ideia de justiça transicional em nosso país.

Uma iniciativa extremamente positiva é a organização de caravanas da anistia. O Ministério da Justiça por meio da Comissão de Anistia realiza encontros nos estados para promoverem os julgamentos de pedidos de perseguidos políticos o que representa um momento de maior visibilidade de tais pedidos junto aos estados em que tais pessoas atuaram na resistência à ditadura ${ }^{4}$. Com isso, é possível a presença de estudantes, sociedade civil de maneira geral e ampla divulgação na imprensa local acerca da memória de tal período histórico.

É possível afirmar então que o Estado tem sido um protagonista importante no sentido de criar canais de viabilização de avanços no campo da memória. No entanto, é preciso ampliar tais espaços e buscar na sociedade práticas que estejam sendo desenvolvidas e que tenham potencial de agregar valor ao resgate da memória. Neste sentido, cabe mencionar o projeto Marcas da Memória,

\footnotetext{
${ }^{4}$ Com a presença de tais caravanas incentiva-se a criação de espaços de memória nos estados. Por exemplo, a criação de fóruns, que funcionam como espaços de constante diálogo sobre questões relacionadas ao período da Ditadura militar, bem como o resgate à memória das atrocidades ocorridas nesse período. Assim, é possível descrever que o fórum possui grande relevância para a efetivação da justiça de transição, já que gera oportunidade para as próprias memórias vivas participarem e relatarem o ocorrido.
}

que vem sendo desenvolvido pela Comissão de Anistia com o objetivo de estabelecer parcerias com a sociedade civil para potencializar múltiplos canais de acesso à memória e envolver os sujeitos sociais nesta tarefa.

Dentre as frentes desenvolvidas é possível citar a elaboração de entrevistas com pessoas que estiveram envolvidas com a luta contra a Ditadura militar e que tiveram algum tipo de reparação pela Lei $10.559 / 02$. Torna-se relevante, na medida em que tais narrativas vão sendo organizadas, a constituição do corpus da memória que poderá ser acessado por gerações futuras. Outra iniciativa importante tem sido as publicações com a contribuição de estudiosos do tema, trazendo reflexões sobre a temática da justiça de transição. Tais obras podem ser acessadas pela internet ou requisitadas junto ao Ministério da Justiça.

Ainda a título exemplificativo, cabe mencionar a implementação de núcleos de assistência às vítimas sob o prisma psicológico (Projeto Clínica do Testemunho). Também merece destaque a atuação do projeto no sentido de fomentar iniciativas da sociedade para a ampliação das vias de resgate da memória por meio de editais. Esta aproximação entre Estado e sociedade poderá produzir resultados extremamente positivos, já que fomenta uma constante reflexão e desenvolvimento de atos concretos de valorização das memórias reveladas.

Também não podemos deixar de mencionar o avanço ocorrido com a instauração da Comissão Nacional da Verdade, cuja tarefa central é elaborar um relatório oficial sobre as violações aos direitos humanos ocorridos na Ditadura militar. É importante salientar que a implementação da comissão referida veio como uma tentativa de resposta à condenação sofrida pelo Brasil na Corte Interamericana de Direitos Humanos, em 24 de novembro de 2010, no caso Julia 
Gomes Lund e outros ${ }^{5}$. O país foi condenado pelas graves violações cometidas durante o Regime militar e, especialmente, relacionado à atuação na Guerrilha do Araguaia, em que cerca de 70 pessoas (ligadas ao $\mathrm{PC}$ do $\mathrm{B}$ ) foram para a região conhecida como bico do papagaio, localizada entre os estados do Pará, Maranhão e Tocantins. Houve grande repressão militar a tal movimento com a atuação de milhares de agentes do estado, o que resultou no extermínio da guerrilha.

Dentre os aspectos mencionados na decisão condenatória dada ao Brasil, temos a determinação de que o Estado proceda à investigação dos fatos (com a responsabilização penal), que empregue todos os esforços para determinar o paradeiro das vítimas de desaparecimento forçado com a identificação dos restos mortais e entrega às famílias e que dê continuidade à elaboração de estudos e relatórios relacionados não só à guerrilha, mas também às violações do período de ditadura militar.

\footnotetext{
${ }^{5}$ Em 2010, assistimos a uma batalha entre dois órgãos jurisdicionais que não possuem qualquer tipo de relação de subordinação entre si que forneceram soluções opostas para o mesmo problema. No caso específico o que está em jogo é a investigação e punição dos militares que praticaram crimes contra os direitos humanos durante a ditadura militar brasileira. Mais especificamente, discute-se a validade jurídica da Lei de Anistia, promulgada em 1979, que está servindo como desculpa para impedir a busca da responsabilidade penal dos militares. De um lado, o Supremo Tribunal Federal, em abril de 2010, decidiu que a Lei de Anistia está valendo, de modo que os militares não podem ser processados ou condenados. Do outro lado do ringue, está a Corte Interamericana de Direitos Humanos que decidiu, em novembro de 2010, que a não-punição dos militares configura violação às convenções internacionais de direitos humanos ratificadas pelo Brasil. Vide em CIDH, Caso Gomes Lund e outros ("Guerrilha do Araguaia") vs. Brasil e STF, ADPF $153 / 2008$.
}

Diante da síntese elaborada é possível concluir que dispomos de importantes instrumentos para que se caminhe no sentido de um fortalecimento da justiça de transição em nosso país. No entanto, só iremos criar uma verdadeira memória cultural acerca das lesões ocorridas durante o Regime militar se investirmos num projeto educativo amplo, envolvendo a escola e outros espaços sociais.

\section{A MEMÓRIA COMO ELEMENTO FUNDAMENTAL DE UM PROJETO EDUCATIVO EMANCIPATÓRIO}

Ainda temos inúmeras pessoas que sofreram diretamente os efeitos da violência do Regime militar que constituem memórias vivas e que precisam de espaços para publicização de suas narrativas, não podendo ficar restritas ao âmbito de suas famílias e amigos. É preciso que sejam criados mais espaços para que essas memórias possam ser trazidas ao conhecimento das novas gerações $^{6}$. Na pesquisa realizada no Estado do Espírito Santo, foi possível estabelecer um diálogo extremamente rico com pessoas que foram perseguidas e que narraram suas lutas, seus dramas e traumas, da mesma forma manifestaram-se acerca de suas percepções de processos julgados pela comissão de anistia.

No que tange aos objetivos almejados com a resistência, pode-se depreender um ponto comum nos depoimentos dos anistiados, qual seja o estabelecimento da democracia no país, como regime político. Por intermédio das

\footnotetext{
6 Os dados que se seguem foram extraídos da pesquisa realizada junto ao Programa de Iniciação Científica da faculdade de Direito de Vitória, sob minha coordenação, com as alunas Juliana Oliveira Ribeiro e Priscila Tinelli Pinheiro. A pesquisa consistiu na análise da narrativa de perseguidos políticos que atuaram na resistência no Estado do Espírito Santo. Serão mencionados apenas alguns dos relatos levantados, bem como das questões que foram narradas e que estão relacionadas ao foco do presente artigo.
} 
manifestações, acreditava-se que seria possível alcançar maior participação popular nas decisões políticas e, consequentemente, um governo com maior liberdade de expressão. Vejamos alguns relatos:

Relato 1: nós tínhamos os chamados objetivos estratégicos e os objetivos táticos. O objetivo tático era a restauração da democracia no país, por meio de eleições livres, representatividade em todos os níveis, direito de voto para todos os cidadãos, inclusive para os analfabetos, mais liberdade, anistia, fim da ditadura militar, fim do AI 5, eram propostas de momento e os objetivos estratégicos, ao longo prazo era o de alcançar o socialismo.

Relato 2: as lutas das quais participei visavam levar os grupos (estudantes, operários, moradores de bairros) que lutavam por seus direitos a tomarem consciência da falta de liberdades políticas. O objetivo final seria uma insurreição e queda da ditadura.

Quando perguntados sobre os danos sofridos (tanto materiais quanto psicológicos) houve os mais variados relatos, porém é consenso entre eles a violência física/psicológica e os prejuízos econômicos sofridos.

Os danos relatados passam por torturas físicas, tais como aplicação de choques elétricos, "telefones" (socos na altura dos ouvidos), utilização de sons altos e ausência de luz e vão até as torturas psicológicas, por exemplo, realização de ameaças com familiares, utilização de animais como forma de amedrontamento, forçar a pessoa a se despir, dentre outras. Desse modo, é válido analisarmos alguns relatos dos entrevistados

Relato 1: Entre 8 dezembro de 1971 e julho de 1972 estive em prisões do Exército de Belo Horizonte, Rio de Janeiro e Juiz de Fora, e em uma casa de torturas em Petrópolis. As torturas incluíam: ser colocada despida em pau de arara, levar choques elétricos, afogamento, golpes nos ouvidos (telefone sem fio) e nas pernas, injetar líquido que queima no rosto, colocar uma cobra sobre o corpo, ficar em uma "geladeira" (local muito frio, escuro e apertado, ouvindo sons graves e agudos ensurdecedores), sofrer ameaça de novos sofrimentos e de ver meus pais e familiares serem torturados, ter um revolver colocado no ouvido com ameaça de morte, ser espetada por agulhas, ser colocada ao lado de pessoas que conhecia e eram torturadas para acusá-la, ficar sem comer, beber água, ser impedida de dormir, receber visitas constantes de torturadores, brutais ou que fingiam ser "bonzinhos".

Observamos nos vários relatos a ampla utilização de tortura, que coisifica os indivíduos e anula qualquer resquício de respeito à dignidade por parte de quem a pratica e sofre. Neste sentido, contribui Maria Rita Kehl (2010, p. 130):

um corpo torturado é um corpo roubado ao seu próprio controle; corpo dissociado de um sujeito, transformado em objeto nas mãos poderosas do outro - seja o Estado ou o criminoso comum [...]. A fala que representa o sujeito deixa de lhe pertencer, uma vez que o torturador pode arrancar de sua vítima a palavra que ele quer ouvir, e não a que o sujeito teria a dizer. Resta ao sujeito preso ao corpo que sofre nas mãos do outro o silêncio, como última forma do domínio de si, até o limite da morte.

Sob o aspecto econômico, os perseguidos sofreram os mais variados tipos de prejuízo com consequências que ainda hoje produzem efeitos em suas vidas:

Relato 1: o prejuízo de ordem prática enfrentado, foi o atraso de 6 anos na formação [...], não pude me especializar depois de me formar, pois tive que cair no trabalho, enquanto meus colegas iam para o exterior fazer cursos e outros faziam residência, sem falar nos prejuízos financeiros porque ficar 5 anos foragido causam, fora os prejuízos emocionais, de toda ordem, minhas coleções de jornais ficaram perdidas, perdi documentos nas fugas. 
Relato 2: em primeiro lugar me reporto às torturas, que deixaram sequelas físicas e mentais: perda de audição, provocada por ruptura dos tímpanos nas seções de tortura (um deles provocava crises de labirintite e foi reconstituído cirurgicamente); tremedeiras diante de situações que lembravam os eventos passados, pesadelos frequentes etc. Em segundo lugar devo me referir às perdas materiais minhas e de meus pais. Custos com deslocamentos constantes para Belo Horizonte e para o Rio de Janeiro para me procurar, e depois me visitar e discutir com advogados, tendo que recusar serviços que podiam render dinheiro. Custas com processos, com remédios, com cirurgia reparadora da audição, etc. O afastamento do país por seis anos, também custou caro. Finalmente, perdas no tempo e valor da aposentadoria. Por perseguições do SNI e dos demais serviços de segurança tive de abandonar três empregos e sair do país em agosto de 1975, só retornando em julho de 1981 (FRANCISCHETTO, 2018, p. 205 destaques nossos).

Outro entrevistado nos relatou que ficou impossibilitado de prestar concurso público, pois havia um atestado de idoneidade ideológica dentre os documentos exigidos para os candidatos, o qual certamente seria um obstáculo, já que ele estava na condição de perseguido político pelo governo da época.

Em relação à reparação recebida pelos entrevistados anistiados pela comissão de anistia, um ponto em comum é a satisfação com o reconhecimento pelo Estado dos erros cometidos no passado, porém, dois entrevistados alegaram suas insatisfações em determinados pontos da decisão concedida. Nesse contexto, é válido exemplificar:

Relato 1: o simples fato de ter sido criado a Comissão de Anistia, e ter analisado seu processo e ter reconhecido a culpa do Governo para mim, já é gratificante, pois o Estado reconhece o seu erro. Para mim, só o reconhecimento já é o bastante.
Relato 2: a decisão não consegue reparar todas as perdas sofridas do ponto de vista material e psicológico. Participei ativamente na luta histórica pela democracia no Brasil, as marcas na minha vida deixadas por este período de lutas, perseguições e tortura foram muito grandes. $\mathrm{E} \mathrm{o}$ sofrimento se estendeu a minha família. Uma reparação, condizente parcialmente com a renda que teria auferido se meus direitos tivessem sido respeitados, trazem, porém, uma sensação de justiça e amparo para alguém como eu já sexagenária. Felizmente pude viver para ver isso (FRANCISCHETTO, 2018, p. 207).

Assim, é importante destacarmos o valor da reparação para a efetividade da Justiça de Transição, visto que a maior parte dos perseguidos políticos não estava interessada na reparação pecuniária, mas sim na atenção dada pelo Estado de investigar, julgar os inúmeros atos de tortura ocorridos no passado e, principalmente, reconhecer o seu erro.

No que tange às medidas de nãorepetição, podemos destacar dois pontos de grande relevância para que não ocorra, de fato, a repetição. Um deles é o conhecimento do fato vivido e o segundo é a memória desse acontecimento. $\mathrm{Na}$ pesquisa realizada, também foi perguntado aos perseguidos políticos a que eles atribuiriam o desconhecimento e/ou indiferença com os fatos ocorridos na Ditadura militar. Nesse contexto, para alguns deles isso pode ser atribuído à mídia, a qual não possui interesse de relatar sobre esse período. Um relato muito interessante de um entrevistado declara um motivo que pode ser agregado a essa falta de interesse da mídia em relação ao tema.

Há um temor muito grande sobre a ditadura, pois muitos protagonistas estão vivos ainda. Assim, o conjunto de força política e econômica apoiou a ditadura tem muita força para pressionar e fazer com que a sociedade não tenha o conhecimento do ocorrido nesse período (FRANCISCHETTO, 2018, p. 209). 
Também esteve presente na fala de vários entrevistados a responsabilidade da escola em resgatar a memória de tal período. Um dos entrevistados sugere que "deveria fazer parte do currículo escolar, a história da repressão política, para que os jovens saibam o que é uma ditadura". Portanto, conforme alguns entrevistados

Relato 1: somos desinformados, lemos pouco, discutimos pouco. Conhecemos pouco o funcionamento do poder e nossos direitos e deveres políticos. Por isso somos governados por uma elite política que desonra o país. Entendo que a história precisa ser recontada, revista e analisada para que os entes queridos dos que desapareceram e que ainda vivem possam ter algum sossego e para que os que não nasceram naquela época possam conhecer a verdadeira história deste país e evitar, que tais fatos se repitam. A escola não tem cumprido este papel e mal ensina os brasileiros pobres a ler e calcular. $\mathrm{O}$ conhecimento da verdade é necessário, não para punir criminalmente os responsáveis pelo terror, inclusive também praticado por alguns membros de uma esquerda autoritária. Mas para que as futuras gerações lutem pelo respeito ao pensamento das minorias, dos que se opõe às suas ideias. Sem isso não é possível a convivência saudável entre os cidadãos diferentes de uma nação.

Relato 2: o grande desconhecimento das pessoas acerca da perseguição política que houve no Espírito Santo durante o período militar faz parte de um jogo político de dominação. Se o povo souber vai recriminar. A televisão também é responsável, sendo que o sistema Globo foi um instrumento de divulgação da ditadura, por isso deve uma resposta ao país. E, também, as escolas deveriam ter um trabalho sistemático para esclarecer o que foi o período da ditadura (FRANCISCHETTO, 2018, p. 210).

O que podemos perceber é uma atribuição de grande responsabilidade da escola em ser um espaço privilegiado (já que crianças e jovens passam vários anos em contato direto com ela) para a valorização da memória. Aqui, o foco está voltado para as atrocidades cometidas durante o Regime militar, mas podemos estender a análise para tantos outros temas que ficaram invisibilizados na história do nosso país. Não podemos negar a importância do ensino formal em contribuir para este projeto educativo, mas sabemos que um projeto educativo pensado de maneira mais ampla necessita de inúmeros outros espaços/tempos para que consiga contribuir no processo de conscientização dos indivíduos.

Boaventura de Sousa Santos falanos do que seria tal projeto:

O projeto educativo emancipatório é um projeto de aprendizagem de conhecimentos conflitantes com o objetivo de, através dele, produzir imagens radicais e desestabilizadoras dos conflitos sociais em que se traduziram no passado, imagens capazes de potenciar a indignação e a rebeldia. Educação, pois, para o inconformismo, para um tipo de subjetividade que submete a uma hermenêutica de suspeita a repetição do presente, que recusa a trivialização do sofrimento e da opressão e veja neles o resultado de indesculpáveis opções (SILVA, 1996, p. 17-18).

Macedo (2018) corrobora sobre o papel que a escola faz para um projeto emancipatório:

A escola tem o papel, assim como as instituições familiares e religiosas, em regular os diversos aspectos da sociedade. Tomando por base que a instituição primaz, a família, é dela que partem os valores morais e éticos, que por via introduz a consciência cidadã, a consciência social e principalmente o respeito a diversidade. Em seguida, as instituições religiosas, criadas a partir das lacunas metafísicas da vida em sociedade, uma gama de religiões e seitas baseada em dogmas, crenças e tradições. (MACEDO, 2018, p. 180).

A escola é uma peça fundamental nesta engrenagem que objetiva resgatar a memória. No entanto, não se pode pensar numa escola que, ao contrário, tem servido 
muito mais para a repetição de uma visão linear da história e com inúmeros silenciamentos quanto a memórias outras que não apenas aquelas que fazer parte da versão oficial. Assim:

(...) a sala de aula tem de transformarse ela própria em campo de possibilidades de conhecimento dentro do qual há que optar. Optam os alunos tanto quanto os professores e as opções de uns e outros não têm de coincidir nem são irreversíveis. As opções não assentam exclusivamente em ideias já que as ideias deixaram de ser desestabilizadoras no nosso tempo. Assentam igualmente em emoções, sentimentos e paixões que conferem aos conteúdos curriculares sentidos inesgotáveis. Só assim é possível produzir imagens desestabilizadoras que alimentem o inconformismo perante um presente que se repete, repetindo as opções indesculpáveis do passado. (SANTOS, 1996, p. 18)

Para que possamos desenvolver um projeto educativo que tenha efetivamente potencial de favorecer a tomada de consciência, entendemos não ser suficiente apenas a discussão teórica em sala de aula ou a mera leitura dos manuais de história. É preciso uma ampla análise das diversas fontes de onde emanam memórias para que os próprios indivíduos possam resignificálas diante do presente em que vivem.

Esse olhar produzirá imagens desestabilizadoras susceptíveis de desenvolver nos estudantes e nos professores a capacidade de espanto e de indignação e a vontade de rebeldia e de inconformismo. Essa capacidade e essa vontade serão fundamentais para olhar com empenho os modelos dominados ou emergentes através dos quais é possível aprender um novo tipo de relacionamento entre saberes e, portanto, entre pessoas e entre grupos sociais. Um relacionamento mais igualitário, mais justo que nos faça aprender o mundo de modo edificante, emancipatório e multicultural. Será este o critério último da boa e da má aprendizagem (SANTOS 1996, p. 33).
Assim, o critério a ser utilizado para que possamos saber se houve uma boa aprendizagem não está ligado à repetição de datas e fatos históricos descontextualizados, mas sim a real possibilidade de produzir nos estudantes o questionamento, a análise e o confronto com a realidade, refletindo sobre as formas de violência que hoje são verificadas e as permanências históricas que podem ser associadas às violências cometidas no passado.

\section{REFERÊNCIAS}

BRASIL. Constituição da República Federativa do Brasil. Brasília, DF: Senado Federal: Centro Gráfico, 1988. 292 p. BRASIL. Constituição (1988).

DANTAS, Fabiana Santos. Direito Fundamental à memória. Curitiba: Juruá, 2010.

FRANCISCHETTO, Gilsilene Passon Picoretti. Construção de ecologias de saberes e práticas: diálogos com Boaventura de Sousa Santos. 01. ed. Vitória: FDV Publicações, 2018. v. 01. 368p.

HALBWACHS, Maurice. A memória coletiva. São Paulo: Revista dos tribunais, 1990.

KEHL, Maria Rita. Tortura e sintoma social. In: TELES, Edson; SAFATLE, Vladimir (Orgs.). O que resta da ditadura: a exceção brasileira, São Paulo: Boitempo, 2010.

\section{MACEDO, Y. M. (Org.). Universalização} Transversal: Múltiplos olhares educativos. 2. ed. Belo Horizonte: Nandyala, 2018. v. 1. 240p.

SANTOS, Boaventura de Sousa et al (Orgs). Repressão e memória política no contexto Ibero-Americano: estudos sobre Brasil, Guatemala, Moçambique, Peru e Portugal. Brasília: Ministério da justiça; 
Portugal: Universidade de Coimbra, centro de estudos Sociais, 2010.

SANTOS, Boaventura de Sousa. Para uma Pedagogia do conflito. In: SILVA, Luiz Heron, et al (Orgs). Novos mapas culturais, novas perspectivas educacionais. Porto Alegre: Sulina, 1996.

SANTOS, Boaventura de Sousa. A Gramática do tempo. Pra uma nova cultura política. São Paulo: Cortez, 2006.

SILVA FILHO, José Carlos Moreira da. Dever de memória e a construção da história viva: a atuação da comissão de anistia do Brasil na concretização do direito à memória e à verdade. In: SANTOS, Boaventura de Sousa et al (Orgs). Repressão e memória política no contexto Ibero-Americano: estudos sobre Brasil, Guatemala, Moçambique, Peru e Portugal. Brasília: Ministério da justiça; Portugal: Universidade de Coimbra, centro de estudos Sociais, 2010. 